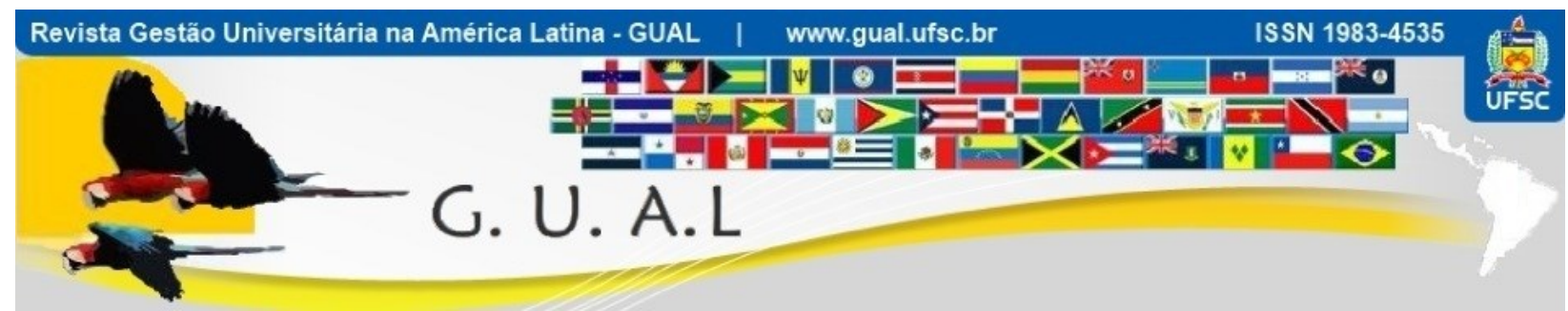

DOI: http://dx.doi.org/10.5007/1983-4535.2013v6n4p49

\title{
SER OU NÃO SER: OS CONFLITOS FUNCIONAIS DO PROFISSIONAL NO CONTEXTO DAS ESCOLAS DE ENSINO SUPERIOR NO BRASIL
}

\author{
TO BE OR NOT TO BE: THE FUNCTIONAL CONFLICTS FACED BY \\ PROFESSORS OF HIGHER EDUCATION IN BRAZIL
}

Jalmir Pinheiro de Souza Júnior, Mestre Universidade Federal Rural de Pernambuco - UFRPE jalmirpinheiro@yahoo.com.br

Betânia Araújo Cosme dos Santos, Doutora Universidade Federal Rural de Pernambuco - UFRPE betaniaacsantos@hotmail.com

Ricardo Brauer Vigoderis, Doutor Universidade Federal Rural de Pernambuco - UFRPE vigoderis@yahoo.com.br

Heloísa Fernanda da Silva Santos, Graduada Universidade Federal de Alagoas - UFAL heloisasantos@hotmail.com

Mônica Calixto Ribeiro de Holanda, Doutora Universidade Federal Rural de Pernambuco - UFRPE holandamcr@yahoo.com.br

Recebido em 29/novembro/2013

Aprovado em 29/novembro/2013

Sistema de Avaliação: Double Blind Review

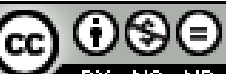

Esta obra está sob uma Licença Creative Commons Atribuição-Uso. 


\title{
RESUMO
}

As instituições de ensino superior brasileiras vêm passando por sucessivas mudanças desde a implementação da LDB, e consequente atuação do professor alicerçada na tríade ensino, pesquisa e extensão. Um processo de transformação em direção a conceber a universidade como empresa, orientada para as demandas do mercado, com cobranças por maior produtividade ganhou força. Este estudo qualitativo, interpretativista, visa ampliar a discussão dos impactos que este cenário tem causado nos docentes, e na realização da prática docente. Foram entrevistados nove docentes que se posicionaram por meio da exposição da experiência já vivenciada na sua atuação cotidiana. Os resultados, pós análise do discurso, evidenciaram a situação preocupante em que se encontra a classe de professores de ensino superior no Brasil, passando por frustrações e insatisfações, no campo profissional, que só fazem estimular o individualismo, aguçar a competitividade entre colegas, e a conseqüente queda na qualidade das relações estabelecidas entre alunos e professores. A desmotivação profissional tem se intensificado a cada período e é ilustrado pelo aumento dos conflitos e pela inquietação com a qual muitos já convivem, na dúvida iminente por ser ou não ser um professor universitário.

Palavras-chave: Ensino Superior. Professor reflexivo. Produtividade acadêmica.

\begin{abstract}
The Brazilian higher education institutions have undergone successive changes since the implementation of the LDB, and consequent action founded on the triad of teaching, research and extension. A transformation process towards conceiving the university as a company that meets the demands of the market, with charges for higher productivity gained strength. This qualitative and interpretive study aims to broaden the discussion of the impact that this scenario has had on teachers and their practice. Nine professors were interviewed and reported the experiences in their daily work routine. The results - after analysis of speech highlighted the worrying situation in which the professors of higher education in Brazil are at the moment. It showed frustrations and dissatisfactions in the professional field that only stimulate individualism, sharpen competitiveness amongst peers, and consequently affect the quality of the relationship between students and teachers. The professional demotivation has been intensified with each period and is illustrated by the increase in conflicts and unrest with which many already live, in imminent doubt in to be or not to be a college professor.
\end{abstract}

Keywords: College education. Reflective teacher. Academic productivity. 


\section{SER OU NÃO SER: OS CONFLITOS FUNCIONAIS DO PROFISSIONAL NO CONTEXTO DAS

\section{INTRODUÇÃO}

Originalmente ser professor, até pela tradicionalidade da profissão, implica em trazer consigo a incumbência de ensinar, de repassar conhecimento, de promover o desenvolvimento dos indivíduos e consequentemente de todo o ambiente onde este está inserido e estabelece suas relações sociais. Porém o perfil lírico e romântico que envolve o ato de ensinar vem perdendo espaço para um cenário onde imperam ordenamentos imperativos representados pela objetividade e pela produtividade.

A docência em escolas de nível superior é, salvo raras exceções, resultante de um processo de formação que é composto por etapas difíceis que visam dar ao profissional embasamento técnico e teórico de alto nível, envolvendo-o em atividades de ensino, pesquisa e extensão. Porém tais etapas nem sempre são eficientes no que se refere a conferir ao producente a conscientização necessária ao "ser professor", mesmo após uma profícua produção científica.

Destarte, é mais comum do que se imagina, encontrar profissionais recém doutorados com exímia habilidade para pesquisas e extremamente despreparados para enfrentar as diversidades postulares de uma sala de aula numa universidade, onde o corpo discente tem perfil cada vez mais complexo. E uma vez inserido numa universidade, fazendo parte de seu corpo docente, há necessidade de atuar não apenas como pesquisador, mas sobretudo como professor. É fundamental que haja determinação para desenvolvimento das vertentes necessárias estabelecendo prioridades de acordo com o que se julgar necessário.

É comum também encontrar profissionais que valorizem em excesso o status conferido pelos títulos adquiridos, criando certo distanciamento com as salas de aula e com a prática da docência em si, concentrando esforços na atuação enquanto pesquisador e em alguns casos enquanto extensionista, que proporcionam prestígio não apenas no meio acadêmico, mas também junto à sociedade. A tríade ensino,pesquisa e extensão direciona a atuação do professor universitário, de forma a existirem exigências das mais variadas origens, para que o condicionam a atuar em ambas as áreas, delimitando por conta própria a intensidade e o esforço a ser despendido em prol de cada ação.

Uma universidade, de acordo com Ribeiro (1969) deve priorizar alguns princípios básicos, quais sejam: o respeito aos padrões internacionais de cultivo e difusão do saber; o compromisso permanente com a busca de soluções para os problemas do desenvolvimento global e autônomo da sociedade nacional e; a liberdade de manifestação de pensamento tanto 


\section{SER OU NÃO SER: OS CONFLITOS FUNCIONAIS DO PROFISSIONAL NO CONTEXTO DAS \\ ESCOLAS DE ENSINO SUPERIOR NO BRASIL \\ DOI: http://dx.doi.org/10.5007/1983-4535.2013v6n4p49}

por docentes quanto por estudantes. Tais princípios se traduzem no perfil necessário a um docente no exercício de sua produção, que deve ser o de transmitir conhecimento, prioritariamente, e possibilitar, através de pesquisas, a prestação de serviços à comunidade.

Este estudo, portanto, objetiva investigar como a tríade ensino, pesquisa e extensão tem sido conduzida por docentes de ensino superior e como os mesmos tem lidado, diante dos desafios, especificamente com o desenvolvimento pessoal e profissional, necessários á prática da docência, confrontando dados com reflexões encontradas na literatura disponível, focada nas funções do professor, do pesquisador e do extensionista. E para isto, faz-se fundamental entender inicialmente a universidade brasileira e suas peculiaridades para somente então aprofundar-se nas perspectivas apresentadas pelo relato de professores universitários acerca do problema em questão.

\section{FUNDAMENTAÇÃO TEÓRICA}

\subsection{O ENSINO SUPERIOR BRASILEIRO}

O ensino superior no Brasil passou por mudanças significativas a partir da Lei de Diretrizes e Bases da Educação (9.394/96), passando a ter como base um contexto macroeconômico que integra a economia numa escala mundial, mudando o papel da educação superior. A sociedade voltada para a busca do conhecimento faz com que haja forte pressão para que as universidades se tornem autônomas, independentes do Estado e mais orientadas às exigências mercadológicas. Essas mudanças ocorreram em vários outros países, como forma de seguir reagir à tese defendida pelo Banco Mundial, pautada na defesa da idéia de ser o ensino superior um bem muito mais privado que público, por se tratar de um componente valorizado por pessoas e pelo próprio país, uma vez que propicia aumento na competitividade do mesmo junto ao mercado internacional. Neste novo modelo, setores que são esternos à instituição influenciam na definição de cursos e sobretudo no currículo de tais cursos. (SGUISSARI, 2002).

Neste aspecto, Martins (2000) afirma, porém, que desde o final da década passada, o crescimento da educação superior no Brasil, numa média de $7 \%$ ao ano, produziu uma diversificação da forma de atendimento aos ingressantes, sobretudo na graduação. Há uma situação de hierarquização institucional sem necessariamente o aprimoramento na relação entre o projeto pedagógico das instituições e as reais necessidades do mercado. 


\section{SER OU NÃO SER: OS CONFLITOS FUNCIONAIS DO PROFISSIONAL NO CONTEXTO DAS \\ ESCOLAS DE ENSINO SUPERIOR NO BRASIL \\ DOI: http://dx.doi.org/10.5007/1983-4535.2013v6n4p49}

O artigo 43 da lei de diretrizes e bases estabelece que uma instituição de ensino superior deve ter como finalidade, o ensino, a pesquisa e a extensão, justificando a necessidade de se definir um campo de organização e alternativas de oferecimento e desenvolvimento diversificadas, consistentes e que contemplem tanto os elementos da ciência, como os componentes do ensino.

Para Wood Jr. (2000), a estrutura de ensino e a formação profissional no Brasil são deficientes, não tendo condições de acompanhar as exigências das mudanças ocorridas no mercado de trabalho, considerando a dissonância existente entre o conteúdo das disciplinas, que constam nos currículos, e a rapidez das transformações nos diversos campos do conhecimento científico e tecnológico. O mercado passou, e passa, por intensa evolução imposta pela competitividade crescente, que não foi, e ainda não é, acompanhada pelo formato da educação que é dada aos profissionais (FERREIRA, 1999, SOUZA, 2012).

Assim, as políticas neoliberais que impuseram às universidades o caráter empresarial, fizeram surgir inúmeras fontes de cobranças que desenharam uma nova forma de trabalho para o docente, que passa a ter como função não apenas o ensino, pesquisa e extensão, mas também a de operário capaz de produzir cada vez mais e mais, obedecendo à máquina competitiva digna da acirrada relação existente entre multinacionais industriais.

\subsection{A PRODUTIVIDADE COMO GUIA DE SOBREVIVÊNCIA}

O funcionamento das instituições de ensino superior no Brasil, especificamente as públicas, em função das políticas neoliberais, teve sua autonomia castrada à medida que suas metas, objetivos, índices de produção, e a própria gestão passaram a ser impostos e mensurados por instituições externas à universidade (BOSI, 2007). Houve um aumento insano de horas-aula, diminuição do tempo para mestrados e doutorados e, como agravante, a avaliação do docente passou a ser realizada em grande parte pela quantidade das publicações obtidas, de colóquios e congressos, a multiplicação de comissões e relatórios etc. Desta forma, virada para seu próprio umbigo, mas sem saber onde este se encontra, a universidade operacional opera e por isso mesmo não age (CHAUÍ, 1999; FIÚZA DE MELLO, 2010).

Assim, a pressão exercida para aumentar a quantidade de trabalho dentro da jornada de 40 horas tem se concretizado, principalmente, alicerçada na idéia de que os docentes devem ser "mais produtivos", correspondendo à "produção" a quantidade de "produtos" relacionados ao mercado (aulas, orientações, publicações, projetos, patentes etc.) expelidos pelo docente. 


\section{SER OU NÃO SER: OS CONFLITOS FUNCIONAIS DO PROFISSIONAL NO CONTEXTO DAS \\ ESCOLAS DE ENSINO SUPERIOR NO BRASIL \\ DOI: http://dx.doi.org/10.5007/1983-4535.2013v6n4p49}

Por um lado, evidencia esse processo o direcionamento empresarial da ciência, tecnologia, pesquisa e desenvolvimento, presente nos editais dos órgãos de fomento à produção científica (CHAUÍ, 1999; BOSI, 2007; FIÚZA DE MELLO, 2010).

A própria estrutura organizacional das instituições têm se voltado para o estímulo ao produtivismo, tomando como rotineira repassar responsabilidades que deveriam ser de gestão do Estado, ao condicionante desempenho dos docentes em aprovar projetos em instituições de fomento. Antes, os profissionais deveriam recorrer aos almoxarifados das instituições para obter itens necessários ao seu trabalho, como papel para impressão de textos, canetas, material de limpeza ou itens mais específicos, como álcool, éter, reagentes e vidrarias. Atualmente, os professores devem elaborar projetos de pesquisa ou de extensão universitária para o aparelhamento institucional (GUERRA, 2005; MEZA; SOARES; SALVADORI; TERUYA; DE MEZA, 2012).

Nesse "vale quanto pesa", o próprio docente é "valorizado" pela inserção na pósgraduação, pelo número de orientações, artigos e livros publicados e, principalmente, pela "bolsa produtividade em pesquisa" que consegue por méritos próprios. Ser ou não ser um cientista reconhecido passou a ser um ritual que se repete constantemente, a cada edital. Se parar de publicar, perde-se a bolsa, não se ganha mais auxílio. É excluído do sistema, não interessando o que se fez no passado, mas sim nos últimos dois, três anos (SANTOS, 2004; CHRISPIANO, 2006; BOSI, 2007; MEZA; SOARES; SALVADORI; TERUYA; DE MEZA, 2012).

A pesquisa, de fato, é importante para a formação completa do discente, uma vez que constitui um processo social que perpassa toda vida acadêmica e penetra na medula do professor e do aluno. Sem ela, não há como falar em universidade, se a compreendemos como descoberta e criação. Somente para ensinar, não se faz necessária essa instituição e jamais se deveria atribuir esse nome a entidades que apensas oferecem aulas (DEMO, 2001, 2003). No entanto, a forma como tem sido conduzida, sendo mecanismo de alienação do docente, que vive ávido por quantitativos muitas vezes não ponderando a qualidade do que se produz, nada mais é do que mais um mecanismo a serviço do capital, das políticas neoliberais e das escravização do saber (CHAUÍ, 1999; SEGRERA, 2010).

O ambiente onde está inserido o professor nas instituições de ensino superior encontrase, portanto, com alto nível de pressão que o coloca em situações de muitas vezes, ter que 


\section{SER OU NÃO SER: OS CONFLITOS FUNCIONAIS DO PROFISSIONAL NO CONTEXTO DAS \\ ESCOLAS DE ENSINO SUPERIOR NO BRASIL \\ DOI: http://dx.doi.org/10.5007/1983-4535.2013v6n4p49}

priorizar a pesquisa e a extensão em detrimento ao ensino, e sobretudo, dissociar a tríade, ao buscar resultados que visem publicações e não possibilitar aprendizado ao discente.

A situação torna-se ainda mais preocupante, uma vez que a postura produtivista é adquirida pelo docente ainda em seu processo de formação profissional, através do ritmo imposto pela instituição na qual foi aluno, fazendo com que o mecanismo não apenas seja vivenciado, mas também repassado a cada geração de profissional formado. Em algumas áreas do conhecimento, a reprodução desse comportamento atinge não somente os alunos da pós-graduação, mas repercute também entre alunos da graduação que sofrem, já desde cedo, a pressão para serem competitivos, o que é nocivo às iniciativas criadoras de estudantes e de pesquisadores (NOGUEIRA-MARTINS; FAGNANI NETO; MACEDO; CÍTERO; MARI, 2004; CHRISPIANO, 2006; MEZA; SOARES; SALVADORI; TERUYA; DE MEZA, 2012).

\subsection{AS LACUNAS DO PROCESSO DE CONSTRUÇÃO DE UM DOCENTE}

Uma grande transformação vem-se registrando no ensino superior, não apenas no Brasil, mas também em boa parte do mundo, nos últimos dez anos. A forte expansão, em termos quantitativos, mais marcante em países altamente industrializados, porém presente também nos países em desenvolvimento, gerou problemas novos diante dos quais percebeu-se um despreparado dos educadores. $\mathrm{O}$ ensino que tradicionalmente se caracterizou por ser restrito à elite, vem-se transformando num ritmo acelerado num ensino de massa. Este fato, que é indiscutivelmente uma conquista, propiciou o surgimento de problemas que se caracterizam como autênticos desafios: com conciliar um ensino de massa com um ensino de excelência? Do ponto de vista didático, o problema se coloca na busca de um tipo de organização de situações de ensino e aprendizagem capaz de manter e mesmo melhorar os níveis de eficiência do ensino e, ao mesmo tempo, oferecê-lo a um grande número de alunos." (LUZ; BALZAN, 2012). Estes problemas colocaram em evidência a análise dos requisitos mínimos necessários para o exercício da docência e proporcionaram intenso debate acerca da formação até então oferecida a tais profissionais.

A formação do docente de uma instituição de ensino superior está voltada para uma crescente especialização dentro de uma área especifica do saber, concentrando esforços no aprendizado técnico e teórico. Há, no cenário nacional, pouca ou nenhuma preocupação com a formação pedagógica de mestres e doutores, advindos dos mais variados cursos de pós- 


\section{SER OU NÃO SER: OS CONFLITOS FUNCIONAIS DO PROFISSIONAL NO CONTEXTO DAS \\ ESCOLAS DE ENSINO SUPERIOR NO BRASIL \\ DOI: http://dx.doi.org/10.5007/1983-4535.2013v6n4p49}

graduação. Os cursos de graduação, nas universidades têm recebido cada vez mais docentes titulados, porém, sem a menor competência pedagógica. (VASCONCELOS, 1998).

De acordo com Bernstein \& Solomon (1999), corroborado pelo que pensam Luz e Balzan (2012), o conjunto de regras existentes nos setores pedagógicos das instituições têm estabelecido um certo controle simbólico, que acaba por regular o acesso e a distribuição da consciência, da identidade e do desejo dos docentes. O principal objetivo desta postura reside em tentar controlar a forma por meio da qual o professor constrói sua identidade profissional. A burocratização a hierarquização despreparada têm minado a elaboração de planejamentos pedagógicos discursivos, e preconizando a utilização de cartilhas a serem seguidas, sem a menor contextualização.

Já no que tange aos programas de pós-graduação, observa-se que há uma forte tendência à unicidade de postura voltada prioritariamente para a realização de pesquisas, de forma a não atender às necessidades dos professores nas suas atividades de docência. Os docentes sistematizam e desenvolvem habilidades próprias aos métodos de pesquisa, de acordo com o que se fizer necessário para obtenção de resultados, deixando de lado as características importantes para o desenvolvimento do ensino, do ato de ensinar (CAMILO; RIBAS, 2007).

Em contraposição é importante destacar que, com relação à qualificação dos professores para um ensino de massa, mesmo nos Estados Unidos, o país pioneiro da expansão do ensino superior, o crescimento se deu de forma relativamente lenta e começou muito cedo, o que possibilitou dispor de professores bem qualificados para quase todos, em função de ter havido muito tempo para a preparação (CASTRO, 2006).

Para que o ensino ocorra de forma efetiva, o planejamento pedagógico deve ser construído com a participação dos docentes, tornando-os parte constituinte do processo e trazendo para os mesmos a responsabilidade de fazer do aprendizado agente transformador da sociedade como um todo. Porém este docente deverá ter a formação necessária para atuar de forma reflexiva, não apenas, na elaboração, mas, sobretudo na execução do planejamento pedagógico.

Importante destacar, porém, que a transformação de qualquer indivíduo em um profissional reflexivo não pode ser improvisada. Somente a cultura teórica não se demonstra suficiente, embora seja necessária, para a efetivação deste processo. Para a prática da reflexão, de fato é fundamental a participação do docente em pesquisas, no entanto, essa iniciação em si 


\section{SER OU NÃO SER: OS CONFLITOS FUNCIONAIS DO PROFISSIONAL NO CONTEXTO DAS \\ ESCOLAS DE ENSINO SUPERIOR NO BRASIL \\ DOI: http://dx.doi.org/10.5007/1983-4535.2013v6n4p49}

não constrói os hábitos e as competências de regulação da prática pela reflexão sobre, na e após a ação. A prática reflexiva deve ser um objetivo e constar no currículo de formação de professores (PERRENOUD, 2002; NORRIE; HAMMOND; D'AVRAY; COLLINGTON; FOOK, 2012), o que não ocorre de forma clara e objetiva nos programas de pós-graduação no Brasil, sobretudo aqueles voltados para as ciências agrárias e biológicas, onde a prática da pesquisa tem caráter emblemático e se estabelece como pilar de sustentação para o ensino e extensão.

Ser reflexivo implica em pensar antes das aulas na melhor forma de executá-las, bem como durante as mesmas, na melhor forma de se comunicar de possibilitar trocas, de construir o aprendizado em conjunto, assim como após o término, pensar no que aconteceu, no que observou, no significado que lhe deu e na eventual adopção de outros sentidos (SCHÖN, 1997).

No meio acadêmico o que se observa é a predominância da postura individualista em oposição veemente à construção de um ambiente de cooperação. Vale ressaltar que tal individualismo não é imposto aos professores, pelo contrário, os mesmos adotam esta forma de ser para obtenção de vantagens, contribuindo assim para a reprodução do sistema, mesmo quando o toleram mais ou menos confusamente, sem tanta convicção do que fazem e do que buscam. $\mathrm{O}$ individualismo está inscrito, em ampla medida, na história da organização escolar e do corpo docente (THURLER, 2001; NORRIE; HAMMOND; D'AVRAY; COLLINGTON; FOOK, 2012).

Ainda segundo Thurler (2001), nas instituições de ensino superior, a administração da interação estratégica estabelece relações profissionais que podem ser de três tipos: a balcanização, uma espécie de cooperação em que se formam diversos grupos coesos em si, mas não entre si, de forma que qualquer decisão que consiga atender aos anseios da totalidade dos docentes se torne um desafio praticamente impossível; a grande família, onde a solidariedade e a cooperação são aparentes, mas a interação não se dá de forma completa, não havendo trocas dialógicas de experiências e nem interferências nas práticas pedagógicas adotadas por cada docente; e a colegiatura forçada, que consiste numa cooperação imposta de cima para baixo. Os defensores da colegiatura forçada acreditam ser possível forçar a cooperação e a parceria por via administrativa, desde que isto ocorra de forma gradativa e num logo período de tempo. 


\section{SER OU NÃO SER: OS CONFLITOS FUNCIONAIS DO PROFISSIONAL NO CONTEXTO DAS \\ ESCOLAS DE ENSINO SUPERIOR NO BRASIL \\ DOI: http://dx.doi.org/10.5007/1983-4535.2013v6n4p49}

No entanto, parece evidente, que a simples adoção de uma das três formas de administrar não garantirá a formação continuada de docentes aptos à construção do saber cooperativo, uma vez que isto requer uma série de atitudes em prol da busca pelo melhor relacionamento, que também deve ser trabalhado na base da formação de cada docente, na sua construção curricular. Assim sendo, muitas são as lacunas que permeiam a formação de um docente nas instituições de ensino superior, que devem ser cuidadosamente analisadas, sempre com a contextualização adequada.

\section{PROCEDIMENTOS METODOLÓGICOS}

Neste estudo foram adotados os procedimentos preconizados pela tradição interpretativista, enquanto orientação paradigmática (DENZIN; LINCOLN, 2011). Trata-se de uma pesquisa qualitativa e portanto, não baseada unicamente num conceito teórico, já que o que predomina neste tipo de investigação é exatamente a utilização de várias abordagens teóricas que caracterizem e possibilitem discussões (FLICK, 2009; BAUER; GASKELL, 2011; CRESWELL, 2012).

Foram realizadas entrevistas em profundidade do tipo centrada no problema, de acordo com sugerido por Bauer e Gaskell (2011), com a utilização de um roteiro planejado para auxiliar na sequência narrativa desenvolvida pelo entrevistado. Trata-se de um método bastante útil para dar a entrevista um novo rumo no caso de uma conversa estagnante ou de um tópico improdutivo (FLICK, 2009).

As entrevistas foram realizadas com professores dos cursos de Ciências Agrárias da Unidade Acadêmica de Garanhuns, uma expansão da Universidade Federal Rural de Pernambuco. Não houve definição prévia do tamanho da amostra, optando por defini-la tão logo ocorresse saturação das respostas (FLICK, 2009; BAUER; GASKELL, 2011). Importante evidenciar que tal saturação se deu na oitava entrevista, quando o respondente não mais agregou informações, além das obtidas nas entrevistas anteriores, em relação aos objetivos do estudo delimitados no problema de pesquisa, mas para assegurar-se de tal saturação (BAUER; GASKELL, 2011), realizou-se mais uma, totalizando nove docentes entrevistados.

Para análise dos dados, foi utilizada a análise de discurso baseada em Gill (2002), onde inicialmente procedeu-se a leitura completa dos textos resultantes da transcrição das entrevistas, buscando identificar elementos que fizessem sentido no contexto da abordagem 


\section{SER OU NÃO SER: OS CONFLITOS FUNCIONAIS DO PROFISSIONAL NO CONTEXTO DAS \\ ESCOLAS DE ENSINO SUPERIOR NO BRASIL \\ DOI: http://dx.doi.org/10.5007/1983-4535.2013v6n4p49}

do estudo. Posteriormente foi realizada uma categorização dos textos, separando os discursos que retratassem os conteúdos teóricos orientadores do estudo direta ou indiretamente, levando-se sempre em consideração o contexto em que o trecho analisado está inserido. Assim foi possível trabalhar a visão do professor em relação a estrutura do ensino superior, bem como o papel que vêm desempenhando neste ambiente, correlacionando o que é praticado com a forma por meio da qual deveria ser praticado.

Finalmente foi realizada a análise propriamente dita, em que foram consideradas as categorias de convergência e de variabilidade das informações, procurando padrões de similaridades e de diferenças levantados a partir de cada discurso, ou seja, em relação a cada dimensão, como cada um dos entrevistados se posicionou em relação aos assuntos discutidos.

A cada trecho foi então atribuído um código que permite localizá-lo dentro do corpus, representado por uma letra maiúscula, uma letra minúscula e um intervalo numérico que significam, respectivamente, o entrevistado, a resposta dada pelo entrevistado, em uma sequência a partir de "a", e o intervalo de linhas dentro desta resposta.

Para garantir a qualidade e a consistência do estudo houve preocupação em manter-se a coerência ontológica e epistemológica com o paradigma interpretativista.. Com objetivo de assegurar a consistência dos discursos dos participantes da pesquisa foram utilizadas notas de campo como relatos transcritos e incorporados ao corpus linguístico analisado, das observações de sinais não verbais, reconhecimento de mudanças na entonação da voz, bem como algum sinal enfático captado durante a entrevista. Tais detalhes foram apreendidos e anotados logo após o término de cada entrevista (DENZIN; LINCOLN, 2011; BAUER; GASKELL, 2011). Também como recomendam Denzin e Lincoln (2011) e Bauer e Gaskell (2011) recorreu-se a um outro pesquisador, não tão submerso no universo do estudo, para supervisionar a pesquisa, como uma espécie de auditor.

Foi feita a triangulação a partir de distintas fontes de dados, inspiradas na diversidade (BAUER; GASKELL, 2011), de duas formas, uma intra e outra inter triangulada. A primeira consistiu no próprio acesso à percepção de cada entrevistado quando o pesquisador triangulou as respostas com vistas a identificar inconsistências, consistências, discrepâncias, discordâncias e concordâncias. Já a segunda, ocorreu com a utilização de dois revisores externos para o conteúdo das transcrições. A prática da reflexividade, critério de confiabilidade baseado no exercício de pensar e repensar o fenômeno (Creswell, 2012), foi 


\section{SER OU NÃO SER: OS CONFLITOS FUNCIONAIS DO PROFISSIONAL NO CONTEXTO DAS \\ ESCOLAS DE ENSINO SUPERIOR NO BRASIL \\ DOI: http://dx.doi.org/10.5007/1983-4535.2013v6n4p49}

uma constante em toda esta pesquisa, até mesmo por ser algo inerente ao pensar interpretativista na pesquisa qualitativa.

\section{RESULTADOS E DISCUSSÕES}

Ao analisar as entrevistas dos docentes identificou-se uma percepção bem estabelecida em relação à estrutura hoje existente nas instituições de ensino superior no que se ao sistema vigente e às exigências de produtividade. Os docentes identificam os pontos negativos existentes nesta cultura produtivista (CHAUÍ, 1999; SEGRERA, 2010), mas não apontam nenhum tipo de possibilidade de trilhar um outro caminho, uma vez que consideram de extrema importância conseguir apoio das instituições de fomento, não apenas para conduzir suas pesquisas, mas também para manter as atividades rotineiras através da compra de materiais de consumo não mais fornecidos pela instituição, conforme já salientou Guerra (2005), quando aponta que hoje, professores têm a obrigação de elaborar projetos de pesquisa ou de extensão para compra de insumos que antes eram adquiridos junto aos almoxarifados das instituições. Alguns trechos podem ilustrar esta dicotomia vivenciada pelo docente:

(...) hoje acabo me dedicando mais às pesquisas porque sei que dali vai sair artigo, e preciso disto pra turbinar meu currículo e ter acesso maior às agências financiadoras. (...) e tem também o seguinte: se não aprovo projeto, não consigo nem tinta pra minha impressora junto à universidade. [Cb:2-4]

(...) acredito que o atual sistema é injusto, pois primeiramente privilegia pesquisadores que já possuem extenso número de publicações, o que dificulta ainda mais jovens pesquisadores. Estimula o volume de artigos em detrimento da qualidade dos mesmos. Estimula pesquisas que contribuem quase nada à academia. Estimula a competitividade entre colegas. [Eb: 3-5]

As entrevistas apontam ainda para um desequilíbrio existente no exercício das funções de professor, pesquisador, extensionista, ou até mesmo uma certa confusão de papéis (MEZA; SOARES; SALVADORI; TERUYA; DE MEZA, 2012). Neste particular, o que se observa é que muitos dos docentes têm deixado em segundo plano o exercício no ensino, da aula expositiva. Muitas vezes, têm também sido negligente em associar ensino às atividades de pesquisa e extensão, priorizando sempre o resultado que julga ser o mais seguro, o que atende às exigências do mercado. Há de fato o desenvolvimento da cultura individualista tão bem exposto na obra de Thurler (2001). Educar pela pesquisa deve ter como condição essencial primeira que o profissional da educação seja pesquisador, ou seja, maneje a pesquisa como 
principio cientifico e educativo e a tenha como atitude cotidiana (NORRIE; HAMMOND; D'AVRAY; COLLINGTON; FOOK, 2012). Não se deve buscar um profissional de pesquisa, mas sim um profissional da educação pela pesquisa (DEMO, 2003), e não é este tipo de profissional que os trechos abaixo permitem identificar.

(...) É preciso ter objetividade. Se temos que ser professor, pesquisador e extensionista, precisamos tentar equacionar de acordo com ponderações adequadas, e na busca da solução desta equação, sempre a prática docente é prejudicada, porque é aquela, cujos resultados são sentidos a mais longo prazo. Por exemplo, se publico um artigo, logo isso vai pro meu currículo, se concluo uma disciplina, se tive ou não bom desempenho como professor, vou saber quando? [Ac:4-6]

(...) Não estou satisfeito com meu desempenho como professor, mas tenho consciência de que é o máximo que posso fazer diante do excesso de coisas, de responsabilidades. As vezes fico confuso sem saber qual deve ser minha prioridade, se dar uma boa aula, se escrever um artigo pra revista qualis A, se aprovar um projeto grande, se atuar junto à comunidade através da extensão, enfim... qual deve ser de fato a minha maior responsabilidade? É tudo muito confuso, porque as cobranças vêm de todas as partes. [Dc:2-5]

$\mathrm{O}$ acúmulo de atribuições tem feito com que a prática da ação reflexiva (SCHÖN, 1997) sequer seja considerada por parte dos docentes, que em alguns poucos momentos até chegam a fazer determinados questionamentos, mas que acabam sendo pouco relevantes diante da necessidade de se realizar um número de atividades para o qual não foi preparado e nem recebe apoio da instituição. Esta situação não apenas prejudica a prática da docência (NORRIE; HAMMOND; D'AVRAY; COLLINGTON; FOOK, 2012) como também impede o desenvolvimento pessoal do professor que em muitas situações se vê lidando com frustrações e sentimento de incapacidade. Os trechos a seguir podem evidenciar o quanto o docente encontra-se com dificuldades para o exercício de suas atividades:

(...) tenho dado aulas sem muito planejamento, falta tempo pra elaborar do jeito que gostaria uma boa aula. Tenho projeto de pesquisa e de extensão, e são relatórios e mais relatórios, datas pra entregar isso e aquilo, como dar conta de ser professor, se tenho que ser extensionista, pesquisador e até mesmo secretária administrativa, porque, nem isso o sistema nos dá. Como eu posso refletir alguma coisa, se não consigo nem tempo pra pensar? [He:14]

(...) faço o plano de ensino, de acordo com as normas da universidade e entrego sempre na data certa, mas não consigo segui-lo conforme gostaria, to sempre tendo que fazer adaptações por causa de vários fatores, mas principalmente por falta de tempo pra fazer um bom planejamento. [Ae:2-6] 
(...) Dou tanta aula, to com um monte de experimento em andamento, é tanta coisa, que realmente não consigo guardar o nome dos alunos não. As vezes um me para no corredor pra fazer alguma pergunta, tirar dúvida, e eu fico tentando adivinhar de que disciplina é, de que curso é, enfim... e acho que isso prejudica muito a relação ensino-aprendizagem. Eu mesma não gosto quando alguém não lembra meu nome. [Ie:2-5]

(...) A estrutura de pressão que envolve o ambiente de um professor universitário esta enlouquecedor. $\mathrm{O}$ regime de dedicação exclusiva tem sido levado ao pé da letra, porque acabo sendo exclusivo mesmo pra instituição, não tendo tempo nem pra família. Todo dia a noite em casa to corrigindo provas, ou relatórios ou escrevendo artigos e projetos. E a gente vai se acostumando a essa rotina e nem percebe o quanto nos tornamos alienados. [Bf:1-6]

(...) Não consegui concretizar práticas complementares durante o semestre por falta de motivação e insegurança. [Ef: 3-5]

Em função também do que se apresenta, o professor tem deixado de lado o desenvolvimento da postura colaborativa, de partilhar experiências com os colegas, pelo fato de não haver uma convivência que não seja a importa por reuniões diversas, e muitas vezes cedendo à acomodação. Não há, portanto, a troca de experiências e a partilha de saberes que propiciem o desenvolvimento e a formação mútua, nos quais cada professor é chamado a desempenhar, simultaneamente, o papel de formador e de formando (NORRIE; HAMMOND; D'AVRAY; COLLINGTON; FOOK, 2012). Os trechos comprovam o quanto a individualidade tem levado a situações de comodismo e de insatisfação:

(...) tem uns quatro anos que dou a mesma aula, uso os mesmos slides, não tenho tempo pra rever o conteúdo e melhorar. As poucas vezes que encontro meus colegas de trabalho são nas reuniões onde normalmente são apenas dados informes. [Cf:2-4]

(...) Não sei se os alunos gostam das minhas aulas, na verdade acho que sim, nunca reclamaram. Tem aqui uma comissão que aplica uns questionários para que os alunos avaliem a disciplina ao final, mas nunca recebi nenhum resultado disto, nunca houve um debate ou um feedback sobre a forma como damos aulas. [Bg:1-4]

(...) Bom, sou professor, pesquisador, extensionista, faço serviços administrativos e eventualmente ainda tenho que lidar com aconselhamentos a alguns alunos. Será que to ganhando pra fazer isso tudo? Acho que definitivamente não. [Fg:3-6]

O sistema que prevalece nas instituições de ensino superior público no Brasil tem contribuído para formar docentes cada vez menos reflexivos e cada vez mais mecanizados (CHAUÍ, 1999), que buscam soluções das mais diversas para se enquadrarem nas exigências 
referentes a prazos e conteúdos (MEZA; SOARES; SALVADORI; TERUYA; DE MEZA, 2012). Esta situação, fatalmente reflete também na forma de avaliar os discentes, que muitas vezes não levam em consideração critérios pedagógicos, mas sim adequação a normas e prazos, conforme ilustra o trecho a seguir:

(...) Nunca achei que provas objetivas fossem a melhor forma de avaliar o conhecimento, mas diante do pouco tempo pra fazer correções, e com um calendário tão apertado, acaba sendo a única saída, embora saiba do descontentamento dos alunos em relação a esse tipo de prova, fazer o que, o próprio sistema faz com todos tenhamos que pagar algum preço. [Ch:1-5]

Assim, o que se observa como constante no ambiente de trabalho nas instituições de ensino superior é uma crescente alienação por parte do docente, que acaba não conseguindo separar a vida pessoal da vida profissional, e pior do que isto, tendo desempenhos aquém do que se deseja em ambos os campos. Aliado a estes problemas tem-se ainda o distanciamento na relação professor-aluno que compromete todo o processo de ensino e aprendizagem. Nos trechos abaixo ficam evidentes estas peculiaridades:

(...) Aproveito as férias pra organizar dados e escrever artigos, porque durante o período letivo isso é impossível, mas com certeza minha família acaba sendo prejudicada e naturalmente me cobra maior presença, mas infelizmente tenho que escolher, entre o profissional e o pessoal. [Ih:2-6]

(...) Outro dia um aluno me disse que nunca me acha na minha sala, que to sempre ausente e que nem parece que sou dedicação exclusiva. É como se não soubessem, que além das três disciplinas, tenho que acompanhar dois experimentos, corrigir provas, escrever artigos e escrever relatórios, e ainda ir a reuniões da unidade, enfim, é só cobrança.[Dh:1-5]

\section{CONCLUSÕES}

A questão aqui proposta constitui no grande desafio das instituições de ensino superior públicas no Brasil. Elaborar projetos pedagógicos que possam reconstruir a formação do docente, mesmo no cenário atual, onde a pressão mercadológica das agências de fomento se faz impositiva. É de extrema importância resgatar no docente a busca pelo desenvolvimento pessoal e profissional em todas as vertentes.

É fatual que o que se encontra hoje nas universidades são profissionais insatisfeitos e trabalhando em condições que levam a frustrações e a alienação. A tríade ensino, pesquisa e extensão, não tem sido executada de forma integrada, estando o foco na prática da pesquisa 


\section{SER OU NÃO SER: OS CONFLITOS FUNCIONAIS DO PROFISSIONAL NO CONTEXTO DAS \\ ESCOLAS DE ENSINO SUPERIOR NO BRASIL \\ DOI: http://dx.doi.org/10.5007/1983-4535.2013v6n4p49}

dissociada do ensino, apenas com intuito de obter resultados no curto prazo que possam atender a publicações de artigos, aprovação de projetos, etc.

A prática da docência, a sala de aula, tem sido deixada em segundo plano, restando a esta a dedicação que o tempo permitir. Assim tem-se uma relação professor-aluno cada vez menos sólida e mais distanciada, bem como o aumento de ações arbitrárias e avaliações equivocadas.

Este conjunto de fatores acaba por dificultar a atuação do professor, que também não consegue preparar o aluno nem para o mercado de trabalho, nem para a vida, no sentido de que ele compreenda e emita opiniões sobre os problemas que o rodeiam de forma crítica com base em um processo de reflexão sobre a realidade.

Não se trata de pessimismo em excesso, mas a impressão que se tem é que o ensino superior está submerso numa situação onde predomina má formação pedagógica do professor aliado a ganância desmedida e individualista. Profissionais não reflexivos e reprodutores de pensamentos e ações que ratificam erros e servem somente para atender formalidades impostas pelo mercado estão se multiplicando, sem perceberem que constituem apenas peças substituíveis numa engrenagem viciada em passar uma imagem inclusiva, globalizada e totalizadora, mas que na realidade são pequenos e insustentáveis fragmentos individuais que tendem ao desaparecimento, aqui representado pela alienação em que muitos já vivem, na busca iminente por ser ou não ser um professor universitário.

No que tange às limitações do estudo, destaca-se a necessidade de um aprofundamento e continuação de novas pesquisas que venham contribuir para a ampliar o debate da temática. O método de pesquisa qualitativa tem suas limitações, na medida em que as informações ficam sujeitas a serem percebidas apenas pelo ponto de vista do entrevistado e segundo a compreensão dos pesquisadores (CRESWELL, 2012). Ressalta-se que aqui não se teve a presunção de generalizar resultados, mas ampliar a compreensão de um construto, a partir da percepção de um grupo específico, os respondentes do estudo . Outro fator que merece atenção com relação às limitações da pesquisa diz respeito à escolha intencional de terminados artigos da área, como base orientadora das análises. Neste ponto específico cabe destacar que o que se apresenta é uma leitura particular de tais obras, não querendo de modo algum, generalizar a compreensão das mesmas, mas sim, instigar o leitor a buscar nos originais a sua compreensão do todo. 


\section{SER OU NÃO SER: OS CONFLITOS FUNCIONAIS DO PROFISSIONAL NO CONTEXTO DAS \\ ESCOLAS DE ENSINO SUPERIOR NO BRASIL \\ DOI: http://dx.doi.org/10.5007/1983-4535.2013v6n4p49}

Como recomendações para outras pesquisas, tem-se três principais apontamentos: o primeiro deles é de ordem metodológica, no sentido de estimular a realização de estudos de caráter interpretativo, qualitativo, sobretudo para ampliar a compreensão de construtos referentes à área de educação já estudados sob a ótica do positivismo, mas que fizeram emergir lacunas e novos questionamentos . O segundo apontamento, refere-se à necessidade de replicação deste, por outros pesquisadores, com objetivo de verificar outras perspectivas sobre o mesmo tema. E, finalmente, recomenda-se estudos que abordem em que medida as situações de prestação de serviços públicos no exercício da docência, podem ser influenciadas pelos códigos culturais organizacionais elaborados coletivamente ao longo dos anos.

\section{REFERENCIAL BIBLIOGRÁFICO}

BAUER, M. W; GASKELL, G. (orgs). Pesquisa qualitativa com texto, imagem e som: um manual prático. Petrópolis: Vozes. 9 Ed, 2011.

BERNSTEIN, B.; SOLOMON, J. Pedagogy, identity and the construction of a theory of symbolic control. Basil Bernstein questioned by Joseph Solomon. British Journal of the Sociology of Education, London, v. 20, n. 2, p. 265-279, 1999.

BOSI, A. P. A precarização do trabalho docente nas instituições de ensino superior do Brasil nesses últimos 25 anos. Educ. Soc., Campinas, vol. 28, n. 101, p. 1503-1523, set./dez. 2007

CAMILO, M.; RIBAS, K.M.F. - Formação Docente: Professor Universitário na Atualidade. Revista Eletrônica Lato Sensu - Ano 2, nº1, julho de 2007.

CASTRO, C. M. Ensino de massa: do artesanato à revolução industrial. In: STEINER, João E.; MALNIC, Gerhard (orgs.). Ensino Superior: conceito e dinâmica. São Paulo: Edusp, 2006.

CHAUÍ, M. A universidade operacional. Folha de S. Paulo, São Paulo. Caderno Mais! 9 maio 1999.

CHRISPIANO, J. Todo poder à avaliação. Revista da ADUSP, São Paulo, n. 36, p. 26-35, jan. 2006.

CRESWELL, J. W. Qualitative inquiry and research design: choosing among five approaches. 3. ed. Thousand Oaks: Sage Publications, 2012

DEMO, P. Pesquisa: Princípio Científico e Educativo. 8ª edição. São Paulo. Cortez. 2001.

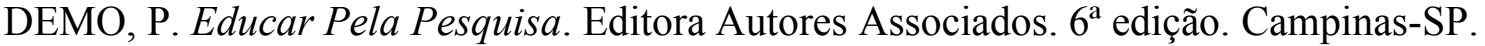
2003.

DENZIN, N. K.; LINCOLN, Y. S. Introduction: entering the field of qualitative research. In: DENZIN, N. K.; LINCOLN, Y. S. (orgs.). Handbook of qualitative research. Sage Publications, 4 Ed. Inc., 2011. 


\section{SER OU NÃO SER: OS CONFLITOS FUNCIONAIS DO PROFISSIONAL NO CONTEXTO DAS \\ ESCOLAS DE ENSINO SUPERIOR NO BRASIL \\ DOI: http://dx.doi.org/10.5007/1983-4535.2013v6n4p49}

FERREIRA, M. Ensino a distância pela Internet. 1999. Acessado em 02/03/2013. Disponível em: http://www.geocities/WallStreet/7939

FIÚZA DE MELLO, A. B. Os sinais de Bolonha e o desafio da construção do espaço latinoamericano de educação superior. La Cuestión Universitária, pp. 125-134, 6, 2010

FLICK, U. Introdução à pesquisa qualitativa. 3.ed. Bookman/Artmed: Porto Alegre, 2009.

GILL, R. Análise de discurso. In: BAUER, M. W.; GASKELL, G. Pesquisa Qualitativa contexto, imagem e som. Petrópolis: Vozes, 2002.

GUERRA, R.F. Impressões sobre a universidade insalubre. Plural, Florianópolis, v. 11, n. 14, p. $4-13,2005$.

LUZ, S. P; BALZAN, N. C. Programa de Formação Continuada para Docentes da Educação Superior: um estudo avaliativo a partir dos resultados de uma tese. Avaliação (Campinas), Sorocaba, v. 17, n. 1, Mar. 2012.

MARTINS, C. B. O ensino superior brasileiro nos anos 90. in: revista são Paulo em Perspectiva. São Paulo, 2000.

MEZA, H; SOARES, J; SALVADORI, A; TERUYA, D; MEZA, M. L. Mecanismos de evaluación en la educación superior brasilera: el caso de la implantación del Sistema Nacional de Evaluación de la Educación Superior - SINAES - los desafios de evaluar un país con dimensión continental. In: Latin American And European Meeting On Organization Studies, 4, 2012, Axixic, México. Anais eletrônicos. Axixic: LAEMOS, 2012. p. 1-19. 1 CD-ROM.

NOGUEIRA-MARTINS, L.A; FAGNANI NETO, R; MACEDO, P.C.M; CÍTERO, V. A; MARI, J.J. The mental health of graduate students at the Federal University of São Paulo: a preliminary report. Brazilian Journal of Medical and Biological Research, Ribeirão Preto, n. 37, p. 1519-1524, 2004.

NORRIE, C; HAMMOND, J; D'AVRAY, L; COLLINGTON, V; FOOK, J. Doing it differently? A review of literature on teaching reflective practice across health and social care professions. Reflective Practice. V. 12. P. 565-578. 2012.

PERRENOUD, P. A prática reflexiva no ofício de professor: profissionalização e razão pedagógica. Porto Alegre: Artmed, 2002.

RIBEIRO D. A universidade necessária. Editora P\&T, São Paulo, 1969.

SANTOS, L.L.C.P. Formação de professores na cultura do desempenho. Educação \& Sociedade, Campinas, v. 25, n. 89, p. 1145-1157, set./dez. 2004 .

SCHÖN, D. Formar professores como profissionais reflexivos. In A. Nóvoa (Ed.), Os professores e a sua formação, $3^{\mathrm{a}}$ ed. Lisboa: Dom Quixote, p.77-91, 1997.

SEGRERA, F. L. Trends and innovations in Higher Education Reform: Worldwide, Latin America and in the Caribbean. Research \& Occasional Paper Series. University of California, Berkeley, p. 1-11, Set. 2010. 
SGUISSARI, V. Educação superior no limiar do novo século: traços internacionais e marcas domésticas. Revista Diálogo Educacional, Curitiba, v. 3, n.7, p. 121-144, set./dez. 2002.

SOUZA, A. R. A natureza política da gestão escolar e as disputas pelo poder na escola. Revista Brasileira de Educação v. 17 n. 49 jan.-abr. 2012

THURLER, M. G. Inovar no interior da escola. Porto Alegre: Artmed, 2001.

VASCONCELOS, Maria Lúcia M. Carvalho. Contribuindo para a formação de professores universitários. Campinas, SP: Papirus, 1998.

WITZEL, A. (2000, January). The problemcentered interview. Forum Qualitative Social Research. (www.qualitative-research.net/fqs-texte/1-00/1-00witzel-d.htm), janeiro, 2000.

WOOD JR, T. Reformando o ensino e o aprendizado de gestão da produção e operações. In: SIMPOI, 2., 2000.São Paulo. Anais... São Paulo: EAG/FGV, 2000. 